\title{
TESTS IN INDUSTRY*
}

By Morris S. Viteues, A. M., University of Pennsylvania

The vocational psychologist concerns himself with finding the right man for the right job. There are two avenues of approach to this: that of choosing a worker to fill a particular job and that of choosing the job which is most suitable for the particular worker. Industry is interested in getting the worker for the job and concerns itself little with the latter and more difficult problem which confronts the vocational counsellor. Both problems, however, involve an analysis of jobs from the point of view of the specific mental abilities which the worker must possess in order to attain proficiency in any one of them and the development of scientifically accurate measures of such ability. "Tests are the devices by which mental abilities can be measured." Industry has lagged far behind education in adopting a quantitative standard for the measurement of the ability of individuals. It has selected the worker haphazardly and the function of selection has often been assigned to one of the menials in the executrve hierarchy of industry. Link, in his Employment Psychology, cites an amusing example of this haphazard method of selecting workers. "One large manufacturing concern," he writes, "has appointed as monarch of the 'hiring-on-window' a man who had the misfortune to lose a leg in the company's employ. As a consequence of this loss he was given his present life job which he performs to the queen's taste. He was induced to describe his methods and they were something as follows. 'On Monday I turns down all the men with white collars, on Tuesdays all with blue eyes, Wednesday all with black eyes. Red-headed men I never hires, and there do be days when I have a grouch and hires every tenth man." This is perhaps an exaggeration, but it illustrates the haphazard method of selection which industry still largely employs. Numerous examples can be cited which illustrate the important part played by the personality and tastes of the employment agent in selection. The head of a billing department of a

* An address delivered at the Conference on "Tests in Relation to Vocational Guidance" at the annual meeting of the National Vocational Guidance Assn., Atlantic City, Feb. 26, 1921. 
department store for which I was preparing tests was praising his force and, took me on a personally conducted tour of his department to point out his star workers. "Now this girl," he said, pointing to one, "is going to make a crackerjack worker I just hired her this week, but I know it. I know that every time I hire a girl with that kind of a face, round, serious looking, smart, she makes a fine biller. Now I must have been asleep when I hired that one. She won't make good," and he indicated a petite, dark-haired girl whose features, in my opinion, radiated intelligence and ablity. The girls whom he had indicated as the possessors of pleasing, intelligent faces to me seemed dull and lifeless. I am free to admit that it was altogether a question of personal tastes, but it was such personal likes which dommated the choice of workers for this department, and for other departments in the store-and resulted in the choice of personnel lacking uniformity and with greatly varying competency for the different jobs in the store

It is by reason of this absence of uniformity in selection that tests are replacing in industry the haphazard method of selection in which the only measure of the applicant's fitness for the job is the judgment of the foreman, or even the better trained judgment of the employment manager on the basis of mere observation. Sometimes those who make the selection are using such additional criteria as the contour of the applicant's face, whether it is convex or concave, the length of the fingers, the texture of the skin, the shape of the head and any number of other unreliable standards which pseudo-scientists are recommending to industrial executives. The readiness of industry to employ these methods is an indication of the need which is felt for some more definite criterion of selection than that of mere observation.

Two kinds of tests are being used by industry to provide these more definite standards of selection;-trade tests and psychological tests. The former are being used to determine whether the applicants for a job in which experience is required actually possesses such experience. They are measures of trade experience involving tasks which only an experienced worker in the trade can perform. The carpenter is given a block of wood, a hammer and a chisel and instructed to make a certain kind of a joint. The inside electrician is given material and is instructed to put up some wiring. Such tests were used extensively in the army during the late war to pick the skilled workers to build cantonments, do electrical wiring, run auto trucks, etc The psychological tests, on the 
other hand, are such as measure the ability of the inexperienced applicant for a position to attain proficiency in the job for which he is applying The dividing line between the two types of tests is not a clear cut one at times, but the fundamental difference is an essential one. I shall confine myself, in this paper, to a discussion of the psychological tests, with particular reference to their use in selection, and not for promotion, transfers, the regulation of wages and any number of other uses to which they are put in industry.

The psychological tests, may be divided into two classes, tests of general intelligence and tests for specific abilities. The general intelligence test, such as the Army Alpha, the Binet Simon test, the Otis test, and many of the so-called intelligence tests which are being used to grade school children are really measures of the performance level of the individual The college professor stands higher on the performance level than the skilled tradesman, and the skilled worker on a higher performance level than the laborer. The higher the performance level of an individual the higher the score he will make on a test for general intelligence, which may be defined as a combination of innate specific abilities, educational and social opportunities. Such tests have a very limited use in industry They are used in the first place, to shut out from employment the feeble-minded, those who are altogether unfit for any job in the plant by reason of deficiency in mentality They are also used to select workers for jobs in which success depends, to a very great extent, upon a high level of general intelligence, namely the executive positions. For selection for the great mass of skilled and semi-skilled jobs, for office jobs and simple clerical jobs, the general intelligence test cannot be used The carpenter and the toolmaker, for example, must stand on approximately the same level with reference to general intelligence, but very different specific abilities are rquired for these trades.

In an analysis of the tests for general intelligence given in the army it was found that laborers and farmers averaged $\mathrm{C}$-in general intelligence; bricklayers, cooks, bakers, general machinists, shop carpenters and workers in a number of other trades averaged $\mathrm{C}$; clerks, photographers, R R clerks, etc., averaged $\mathrm{C}+$. If trade competency correlated with general intelligence it could be predicted that everybody who ranked $C$ in the army alpha would make an equally good bricklayer, cook, baker or general machinist. It is a matter of common experience that many bricklayers could not be trusted to prepare a meal successfully even after much training, and that 
many first class chefs could be taught bricklaying for many years and would never succeed in aligning properly a row of bricks Trade competency is related to specific abilities which the individual possesses. Specific abilities are those innate traits which enable an individual to perform some specialized task. In the schools we find good pupils who are poor in arithmetic, good arithmeticians who do not learn to spell well, and individuals who are poor in spelling, arithmetic, reading and all other school subjects who do remarkably well in the classes in carpentry and clay modelling. A special set of specific abilities go into each of these, and differences in the specific abilities which individuals possess account for differences in arithmetic, spelling, reading competencies and so forth. In the same manner competency for different jobs in industry depends upon specific abilities. A motorman on a trolley car must possess a high degree of distribution of attention, alertness, planfulness and the ability to react quickly with a learned response to external stimuli. The conductor, on the same car, needs distribution of attention, alertness, planfulness in a more limited degree, but the last complex ability is not needed. The conductor on certain roads needs a certain amount of arithmetical competency, the motorman need possess none of this. The general intelligence needed for these two jobs is about the same, but there are many men who make good conductors who would be dangerous characters as motormen by reason of deficiency in the ability to respond with certainty to the stimuli with certain learned responses. A girl who wraps locks must concentrate her attention on one particular object to the exclusion of all others; a girl who inspects locks at the same table must distribute her attention over a number of different elements of the locks. Concentration and distribution of attention are two distinct specific abilities. It was found in one plant that girls changed from one job to the other failed to make good and a psychological analysis of the job explains this failure on the basis of the different specific abilities involved in these jobs The tests which are being used successfully in industry are those which measure the specific abilities of individuals for particular jobs, and not tests for general intelligence.

The process of developing tests for industry is a long one. It involves, first of all, an analysis of the job from the point of view of the abilities involved in its performance. Such an analysis can only be made by a psychologist. In some cases it can be made by merely observing the worker on the job, but in most cases it is actually necessary for the psychologist 
to become a worker, to don the overalls of the machine hand, the gloves of the motorman, the green shade of the clerk if he desires to make an adequate analysis-to understand" "the mental action for which he is trying to find tests as measures" The next step is to find or devise tests which, in his opinion, involves in their performance the same specific abilities which are involved in doing the job For this purpose the psychologist can use, sometimes with only slight modifications many of the tests which are in common use, but it is often necessary for him to construct an entirely new prece of apparatus. Analyzing the job and preparing the test are only preliminary steps in developing the tests for particular jobs There are two additional steps which must be carried out. In the first place the fact that the test is actually a measure of the abilities which the job requires must be empirically demonstrated. In other words, the tests must be tested. This is generally done by submitting workers who are already employed on the job to the test and finding out whether the more proficient workers actually pass the test with a higher score than the less proficient workers Sometimes, a number of tests which seem to involve the same ability are given. and these selected which show a high correlation with proficiency in the job. Another and longer but better method is to test all applicants for the job with the tests which have been selected by the first method, to make a record of their scores on the test, and to follow them up after they are employed at specific intervals to determine whether the individuals who made high scores become proficient workers and vice versa. (In this connection, of course, it must be recognized that there are other factors than inability for which an individual is found unsatisfactory in industry, and that the test measures only this, the most important factor in satisfaction ) The other step is to provide quantrtative standards for selection. The standards must be in terms of units or of times, and the exact point which employment is advisable must be indicated Such points, critical levels they are called, can only be established empirically, and as more applicants are tested the standards so established are revised and refined

It is necessary to recognize that tests which are being used in industry overlook an important feature-temperamental differences between individuals Two men may have the same specific abilities; both may have equal competency for a particular job, but one may be a willing worker, the other may be an unwilling worker. One may be tempera-

${ }^{1}$ Link Employment Psychology 
mentally fitted for the job, the other may not. The first may be fond of indoor work, the second of outdoor work. The vocational psychologist has hardly attempted to measure these temperamental differences, largely because little of concrete value has been accomplished in the analysis of mental qualities which are called temperamental. Both for purposes of selection in industry, as well as in vocational guidance, definite devices for measuring temperamental differences will have to be developed before selection can be extremely satisfactory. ${ }^{2}$ "It must certainly seem," says Watts in an article in the British Journal of Psychology, "that the vocational psychologist will need to take into consideration what has so far been overlooked, the instinctive make-up of the subjects of his experiments, and that in choosing workers for particular tasks he must make sure that their instinctive type is the right one. It would be folly to place the man with strong gregarious tendencies in lighthouse or wireless work, or advise him to go into farming in a new colony, just as it would be unwise to encourage a boy devoid of the acquisitive instinct to set up in business. And it will be agreed that a soldier or a reformer without a considerable spice of pugnacity would be a failure, while it is equally beyond dispute that the statesman and the priest, the doctor and the nurse, the teacher and the shepherd would soon tire of their work if they were not endowed strongly with the tender impulse." The next few years will show whether we shall be able to devise tests for the diagnosis of the relative strength of man's various instinctive qualities. It would be possible to quarrel with Watt's analysis of instinctive qualities, but the essential problem is well stated. In addition to abilities there are motives and purposes in the worker's make-up. There are, as has been popularly stated, " doers who will' and 'doers who won't' and the 'willer' and the 'wonter' present another problem for quantitative treatment with tests." That judgment of temperament made by observation of facial characteristics, color of hair and other physical features, which is recommended and used by popular vocational counsellors, is unreliable is very apparent to the scientist.

One factor in vocational guidance should be the child's competency for the occupation which he seeks or is being advised to enter. The judgment of the counsellor upon the presence of the competency is as unreliable as the judgment of fitness for a job made by the employment agent in indus-

\footnotetext{
2F. Watts "The Outlook for Vocational Psychology" Britusi Jour. of Psychol., Jan., 1921
} 
try. The presence or the absence of such competency can be determined by the use of the same tests which are being used by industry in the selection of its workers. Associations interested in vocational guidance should co-operate with industry and obtain from industrial plants the tests which they are using. Such an association should also undertake an analysis of jobs to determine what constitutes competency for particular jobs and the development of measures of such competency, in the same manner as industry is doing. We have passed the time in vocational guidance when jobs can be defined in terms of such abstract qualities as good, hard, clean, desirable, etc. We have reached the point where an accurate definition and reduction to measurable terms of job competency is absolutely essential.

In the use of tests for vocational guidance it must be recognized, however, that competency for a job, as measured by a test, is only one factor in guidance. It is combined with the child's health, his desires, his temperament, and other conditions to determine final choice of an occupation The test, however, - the same test that industry uses in the selection of workers for its jobs can be used in the place of the harsher method of trial and failure to weed out those who are definitely incompetent to attain proficiency in vocations which otherwise seem suitable and to point the way to those whose desires are not well defined. 